\title{
KVALITATIVNO ISTRAŽIVANJE U OBLASTI PRIMENJENE LINGVISTIKE: VAŽNOST I ZNAČAJ INTERVJUA U ISTRAŽIVANJU JEZIČKE ANSKIOZNOSTI
}

\begin{abstract}
APSTRAKT
Ovaj rad ima za cilj da naglasi značaj upotrebe kvalitativnih metoda istraživanja u oblasti primenjene lingvistike. Kroz detaljan teorijski pregled literature koja potkrepljuje validnost upotrebe kvalitativnih podataka posebna pažnja se posvećuje intervjuu - instrumentu koji daje detaljan i nedvosmislen uvid u perspektivu ispitanika. Praksa je da se u oblasti primenjene lingvistike kvantitativne metode istraživanja često kombinuju sa kvalitativnima kako bi se dobila potpunija slika i kako bi se problem istraživanja sagledao iznutra dajući mogućnost ispitaniku da kroz uobičajeno ponašanje u svom prirodnom okruženju iskaže suštinu problema. Kao primer prethodno spomenutih teorijskih postavki, ovaj rad daje detaljan prikaz upotrebe i značaja kvalitativnih metoda istraživanja $u$ ispitivanju jezičke anksioznosti u razrednoj situaciji i anksioznosti pri komunikaciji među učenicima osnovne škole, pri čemu rezultati dobijeni upotrebom intervjua, kao kvalitativnog instrumenta, utiču na konačno tumačenje rezultata dobijenih kvantitativnim putem.
\end{abstract}

Ključne reči: jezička anksioznosti, anksioznost pri komunikaciji, intervju, kvalitativno istraživanje, engleski jezik kao strani.

QUALITATIVE RESEARCH IN APPLIED LINGUISTICS: THE IMPORTANCE AND SIGNIFICANCE OF THE INTERVIEW IN FOREIGN LANGUAGE ANXIETY RESEARCH

\begin{abstract}
This paper aims to highlight the importance of the use of qualitative research methods in applied linguistics. Through a detailed theoretical review of the literature supporting the validity of the use of qualitative data, special attention is given to the interview - an instrument that gives a detailed and unambiguous insight into the perspective of the respondents.
\end{abstract}


The practice is that in the field of applied linguistics quantitative research methods are often combined with qualitative ones in order to obtain a more complete picture and to visualize the research problem from the inside, by allowing respondents to describe the essence of the problem in their own words. As an example of the aforementioned theoretical assumptions, this paper provides a detailed overview of the use of qualitative research methods in the study of language anxiety in a classroom situation, and communication apprehension among primary school students, wherein the results obtained using the interview, a qualitative instrument, affect the final interpretation of the results obtained by quantitative research.

Keywords: foreign language anxiety, communication apprehension, interview, qualitative research, EFL

\section{UVOD}

U odnosu na kvantitativno istraživanje koje omogućava istraživaču da se upozna s problematikom predmeta istraživanja upotrebom raznih instrumenta i analizom uzročno-posledičnih veza između varijabli, kvalitativno istraživanje je bazirano na naturalističkom principu koji istraživaču omogućuje da problem sagleda iznutra, pri čemu se podaci dobijaju direktno sa terena, dok je istraživač taj koji posmatra aktivnosti i interakcije (Patton 2002: 4).

Rezultati kvalitativnog istraživanja mogu se predstaviti samostalno ili $\mathrm{u}$ kombinaciji sa kvantitativnim podacima. Kvalitativne metode doprinose da predmet istraživanja bude obrađen $\mathrm{u}$ potpunosti i detaljno. $\mathrm{S}$ druge strane, kvantitativne metode zahtevaju upotrebu standardnih mera prema kojima se odgovori ispitanika svrstavaju u prethodno određene kategorije. Prema tome, kvalitativne metode pokušavaju da dopru do srži problema koji se ispituje, što im ograničava mogućnost generalizacije.

U istraživanjima koja kombinuju kvantitativne i kvalitativne instrumente, intervju (kao jedan od najčešće korišćenih instrumenata u kvalitativnom istraživanju) sledi iza urađenih testova i anketa i služi kao odličan kontekst za dublju analizu dobijenih statističkih podataka. Paton (Patton 2002: 342) tvrdi da se ljudi intervjuišu kako bi se dobile informacije koje se ne mogu dobiti posmatranjem, što znači da se upotrebom navedenog instrumenta dobija detaljan uvid u tuđu perspektivu. Prema tome, kvalitativno istraživanje, pa samim tim i intervjuisanje treba da se započne pretpostavkom da je tuđa perspektiva značajna, jasna i da pruža neka nova znanja. 
Oslanjajući se na prethodno navedene činjenice, ovaj rad predstavlja rezultate dobijene kvantitativnim i kvalitativnim putem i na taj način ukazuje na adekvatnost, ali i neophodnost, upotrebe kvalitativnog istraživanja u oblasti primenjene lingvistike, prvenstveno zbog prirode samog predmeta istraživanja. Stoga se rad, koji čini samo deo kompleksnog istraživanja problema jezičke anksioznosti, bazira na analizi jedne od hipoteza u napomeni spomenutog istraživanja koja glasi: Anksioznost pri komunikaciji je izražena među učenicima viših razreda osnovne škole. Rad je zamišljen tako da kroz analizu kvantitativnih i kvalitativnih podataka naglasi važnost i značaj upotrebe intervjua, jer kvantitativni instrumenti, iako pouzdani, ne daju odgovore na ona najbitnija pitanja kao što je zašto, što će se kasnije ispostaviti kao ključno pri analizi i tumačenju podataka.

\section{KVALITATIVNO ISTRAŽIVANJE}

Kvalitativno istraživanje se uglavnom bazira na četiri osnovne metode prikupljanja podataka: (a) učestvovanju, (b) direktnom posmatranju, (c) intervjuisanju i (d) arhivskom istraživanju (Marshall \& Rossman 2006: 97). Pobrojane četiri metode čine primarne načine sakupljanja podataka, koji radi dobijanja bogatijih informacija iz više različitih perspektiva, mogu da se kombinuju sa drugim kvantitativnim metodama, što doprinosi valjanijem prikazivanju stvarnog stanja stvari. Za potrebe ovog rada, autorka se opredelila za upotrebu intervjua, a osnovne karakteristike i prednosti upotrebe istog u oblasti primenjene lingvistike će se detaljno predstaviti u narednom odeljku.

\subsection{Intervju}

Kvalitativni intervjui su uvek otvorenog tipa, mogu da budu strukturisani i nestrukturisani (Schensul 2008: 187), a zajedničko im je to što sadrže pitanja koja omogućavaju ispitaniku da stavove izrazi svojim rečima i što se obično obavljaju na zaštićenim mestima, što ispitaniku nudi privatnost i kod njega stvara osećaj sigurnosti (Radić-Bojanić 2012). Iako ponekad podseća na opušten razgovor, intervju ipak ima svrhu, a to je da se nešto sazna o određenoj temi ili iskustvu učesnika, što se najčešće postiže dijalogom - ispitivač postavlja pitanja, a ispitanik odgovara na njih (Brinkmann 2008: 470). Paton (Patton 2002: 344) naglašava da intervju nikada ne treba da počne listom rutinskih demografskih pitanja, već uobičajenim pitanjima kojima bismo započeli svaki drugi razgovor, 
što za cilj ima da opusti sagovornika. Potom mogu da slede pitanja o sadašnjem ponašanju, aktivnostima ili iskustvu. Neophodno je, takođe, formulisati svako pitanje tako da u sebi sadrži isključivo jednu misao, što će ispitaniku olakšati davanje odgovora i neće odvesti razgovor u drugi pravac. Zato se i kaže da je formulisanje pitanja od izuzetne važnosti za kvalitet odgovora koji se očekuje (Patton 2002: 344). Paton (Patton 2002) posebno naglašava da po svaku cenu treba da se izbegavaju pitanja koja počinju upitnom rečju ,zašto”. Pitanja formulisana na taj način u sebi nose pretpostavku da se nešto dogodilo sa razlogom koji je ispitaniku poznat, što ponekad i nije slučaj. To može dodatno zbuniti ispitanika i situaciju učiniti neugodnom jer ispitanik možda neće imati odgovor. Stoga se predlaže da se pitanja poput: „Zašto ste se pridružili ovom programu?" preoblikuju u: „Šta je to što Vas je najviše privuklo ovom programu? " (Patton 2002: 345). Postavljanje adekvatnih pitanja je veština koja proističe iz iskustva i sigurnosti ispitivača koji zna šta traži iz intervjua koji sprovodi, koji pažljivo osluškuje i ono što je rečeno i ono što nije spomenuto i koji je osetljiv na potrebe osobe koja je intervjuisana. Pored toga, kvalitetna upotreba vremena je takođe veoma dragocena u svakom intervjuu. Da bi vreme bilo u potpunosti iskorišćeno, neophodno je držati konce u svojim rukama na sledeći način: (1) ispitivač treba da zna šta je to što želi da sazna intervjuom, (2) treba da postavlja precizna pitanja (3) treba pažljivo da sluša da bi procenio relevantnost odgovora i (4) neophodno je da pruža verbalnu i neverbalnu podršku osobi koja je intervjuisana (Patton 2002: 345).

Za beleženje intervjua uglavnom se predlaže upotreba diktafona, ali to ne isključuje potrebu za hvatanjem beleški. Upotreba diktafona omogućava bolju koncentraciju tokom intervjua, pri čemu ispitivač može da obrati pažnju na određene delove koje je obeležio u svojoj radnoj sveci, a da pritom ne pokušava da zapiše svaku izgovorenu reč. Treba napomenuti da je vreme neposredno nakon intervjua presudno za verodostojnost kvalitativne istrage. To je vreme koje garantuje kvalitet prikupljenih podataka, tada se beleže detalji o mestu na kojem se intervju odvijao, pod kojim okolnostima, kako su ispitanici reagovali na pitanja i slično.

Ispitivač takođe treba da bude spreman na to da intervju neće uvek proći onako kako je zamišljeno. On će često čuti informacije o stvarima koje nije pitao, a neretko se intervjui pretvaraju u ispovesti, posebno ukoliko se radi o intervjuima koji su poverljive prirode. Zato se i kaže da su kvalitativne metode istraživanja lične, jer naturalistički tip istrage uvodi istraživača u stvarni svet ispitanika, 
otkriva njihove misli i osećaje, te kvalitativna istraga mora da bude dobro odmerena jer ona, za razliku od anketa, testova i drugih vrsta kvantitativnih pristupa, prodire duboko u svest ispitanika.

\subsection{Validnost intervjua}

Dok validnost kvantitativnog istraživanja zavisi od pažljivog sastavljanja instrumenta, u kvalitativnom istraživanju, posebno kada se koristi intervju, osnovni instrument je istraživač, pa verodostojnost upotrebe ovog kvalitativnog instrumenta zavisi od veštine i kompetencije osobe koja obavlja istraživanje na polju rada. Prema tome, kvalitativno istraživanje se bazira na subjektivnim, interpretativnim i kontekstualnim podacima koje kvantitativno istraživanje najčešće isključuje (Auberbach \& Silverstein 2003: 73). S obzirom da je subjektivnost ono što najčešće dovodi u pitanje validnost kvalitativnog istraživanja, istraživači koji su pobornici ove vrste sakupljanja podataka razvili su nekoliko kategorija kojima se dokazuje njegova validnost (Seale 2003: 171).

Jedna od kategorija je deskriptivna validnost (engl. descriptive validity) koja se odnosi na tačnost podataka (Maxwell 1992: 49). Time se podrazumeva da podaci moraju biti identičan prikaz onoga što je ispitanik rekao. Ista preciznost odnosi se i na izveštavanje o prikupljenim podacima, što znači da transkripcija predstavlja identičan prepis onoga što je rečeno. Ipak, upravo zbog transkripcije podataka mnogi deskriptivnu validnost dovode u pitanje, jer transkripcija ostavlja dovoljno prostora za grešku ili izostavljanje podataka. Čak se i za doslovno transkribovan intervju može reći da je nevažeći ukoliko su u njemu izostavljene karakteristike neformalnog govornog jezika, pa čak i naglasak, jer sve to zajedno čini osnovu za pravilno razumevanje i tumačenje intervjua.

Druga kategorija je interpretativna validnost (engl. interpretative validity) i odnosi se na način na koji istraživač tumači značenje događaja, predmeta ili ponašanja (Maxwell 1992: 50). Ovde je ključno da interpretacija bude bazirana na perspektivi ispitanika, nikako ispitivača. To jasno može da se vidi kroz jednostavan primer: ukoliko tokom intervjua ispitanik udari rukom o sto, tumačenje može biti dvojako. Stoga je na ispitivaču da pre donošenja zaključka dokaze o takvom ponašanju pronađe u transkriptu ili govoru tela i tek na osnovu toga zaključi da li je takva reakcija ispitanika bila rezultat ljutnje i besa, ili prosto način da naglasi svoj stav. 
Treću kategoriju čini teorijska validnost (engl. theoretical validity) koja se odnosi na teorijsku osnovu na koju se istraživač poziva ili koju razvija tokom svoje studije (Maxwell 1992: 50). Adekvatna teorijska osnova omogućava istraživaču da pojavu koju istražuje adekvatno objasni. Svi oblici, koncepti, kategorije i karakteristike moraju da se uklope da bi sačinili građu koja će svedočiti o određenoj pojavi. Na primer, ukoliko se u okviru nečijeg istraživanja pojave obrasci netipični za tu pojavu, istraživač bi trebalo da je u mogućnosti da takvu pojavu potkrepi teorijskim dokazima.

Generalizacija (engl. generalizability) je četvrta kategorija koja govori u prilog validnosti kvalitativnog istraživanja, a ujedno je prema Volševim rečima najproblematičnija (Walsh 2003: 70). S obzirom da se kvalitativno istraživanje odnosi na koncept i karakteristike odabrane grupe, zaključuje se da se dobijeni rezultati ili teorijski koncept odnose na sličnu grupu (Auberbach \& Silverstein 2003). Kao što je već pomenuto, razne tehnike sakupljanja podataka, teorijsko potkrepljivanje, biranje odgovarajućeg uzorka itd., dovode do potpunog uvida u problem i do razvoja teorije koja opisuje pojavu koja se ispituje.

Prema tome, istraživač koji odluči da upotrebi intervju kao osnovni instrument na kojem će bazirati svoje kvalitativno istraživanje mora da bude svestan da će podaci njegovog istraživanja biti plod njegovog truda i umeća interpretacije, te da će u njih uvek biti usađena senka njegove ličnosti (Denzin \& Lincoln 2000: 14). Kvalitativni istraživač mora da shvati da je on sastavni deo istraživačkog procesa i jedini odgovoran za rezultate dobijene analizom prikupljenih podataka. Stoga, ukoliko se svesno pridržava onog opisanog u prethodno spomenute četiri kategorije, validnost upotrebe interjvua i kompetencija istraživača ne bi trebalo da budu dovedene u pitanje.

\section{METODOLOGIJA ISTRAŽIVANJA}

\subsection{Metodi sakupljanja podataka}

U okviru istraživanja za doktorsku disertaciju, iz koje je i proistekao ovaj rad, autorka je koristila mešovite metode istraživanja, upotrebljavajući dva instrumenta: anketu i intervju.

Anketa predstavlja prilagođenu verziju Skale za merenje jezičke anksioznosti u razrednoj situaciji (Foreign Language Anxiety Scale) (Horwitz, Horwitz \& Cope 1986) i sastoji se od 12 stavki koje prati trostepena Likertova 
skala. Prema originalnoj verziji pomenute skale, jezička anksioznost koju skala ispituje razlikuje tri međusobno povezane vrste anksioznosti: anksioznost pri komunikaciji, ispitnu anksioznost i strah od negativne društvene evaluacije (Horwitz, Horwitz \& Cope 1986: 127). U okviru rada autorka će upotrebom mešovitih metoda istraživanja utvrditi nivo anksioznosti u razrednoj situaciji uopšte i analizirati anksioznost pri komunikaciji među učenicima šestog razreda osnovne škole, samostalno i kroz uticaj eksternih faktora: pola, ocene i pohađanja privatnih časova.

$\mathrm{S}$ obzirom da anketa, iako jedno od najpouzdanijih sredstava $\mathrm{u}$ kvantitativnom istraživanju, ne daje odgovore na ona najbitnija pitanja kao što je zašto, u empirijski deo istraživanja uvršten je i intervju. Prema tome, druga faza istraživanja se sastoji od 22 intervjua koje je autorka sprovela sa učenicima šestog razreda osnovne škole. S obzirom da je kvalitativno istraživanje sprovedeno sa mlađim učenicima, autorka se odlučila za upotrebu takozvanih fokusnih intervjua (engl. focused interviews), koje su prvi put u teoriji spomenuli Merton, Fisk i Kendal (Merton, Fiske \& Kendall 1956), a koje su kasnije detaljnije opisali i preimenovali u tematske intervjue (engl. theme interviews) finski autori Hirsjervi i Hurme (Hirsjärvi \& Hurme 2001). U okviru istraživanja za ovaj rad korišćen je polu-strukturisani intervju (engl. semi-structured interview) koji je omogućio autorki da podatke prikupi metodom intervjua koji po svojoj strukturi podseća na razgovor. Autorka se odlučila za upotrebu ovakve metode jer su ispitanici, učenici šestog razreda, veoma mladi, a upotrebom ovakve metode omogućeno im je da slobodno izraze svoje mišljenje i iskustvo o temi o kojoj se razgovara. Za potrebe ovog istraživanja tematski intervju je namenski formiran $\mathrm{s}$ ciljem da prati i dopuni anketu koju su učenici prethodno popunili.

\subsection{Uzorak}

Podaci korišćeni u ovom radu su sakupljeni upotrebom mešovitih metoda istraživanja, korišćenjem ankete i intervjua.

Anketom su obuhvaćena 142 učenika šestog razreda osnovne škole „Svetozar Marković Toza“ iz Novog Sada kojima je engleski jezik prvi strani jezik koji uče od prvog razreda osnovne škole. Anketiranje je sprovedeno u toku jednog školskog časa i u učionici, što je doprinelo činjenici da svi upitnici budu popunjeni i vraćeni. 
U kvalitativnom delu istraživanja za ovaj rad učestvovala su 22 ispitanika, učenika šestog razreda Osnovne škole „Svetozar Marković Toza“ iz Novog Sada. Svi učenici su pohađali isto odeljenje. Prema tome, autorka je namernim odabirom uzorka metodom intervjua ispitala 22 učenika šestog razreda osnovne škole s ciljem da se dublje pronikne u problem prisutnosti jezičke anksioznosti na časovima engleskog jezika u osnovnoj školi. Intervjui su snimani video-kamerom, a svi ispitanici su se složili sa tim. Intervjui su sprovedeni na maternjem jeziku ispitanika, tj. na srpskom jeziku. Pre početka intervjua, učenicima su date kratke informacije o cilju ovog istraživanja, da bi se učenici opustili i da se ne bi plašili da iskreno odgovaraju na postavljena pitanja. Autorka je imala za cilj da za vreme kratkog razgovora s učenicima pre intervjua, kao i za vreme njega, stvori opuštenu i prijatnu atmosferu, koja bi ohrabrila učenike da otvoreno govore o osetljivim temama kao što su emocije i negativna iskustva. Intervjui su u proseku trajali od 13 do 24 minuta.

\section{ISTRAŽIVANJE: REZULTATI, ANALIZA I DISKUSIJA}

\subsection{Kvantitativno istraživanje}

S obzirom da se u ovom radu koriste mešovite metode istraživanja, prvo se daje pregled kvantitativnih rezultata dobijenih upotrebom prilagođene verzije skale za merenje jezičke anksioznosti u razrednoj situaciji, a potom i rezultati intervjua. I jedan i drugi instrument su korišćeni s ciljem da istraže da li je i na koji način anksioznost pri komunikaciji izražena među učenicima osnovne škole.

Upotrebom ankete koja se bazira na trostepenoj Likertovoj skali jasno je da je prosečna vrednost 1,5 , a prema tome, prisutnost jezičke anksioznosti je vidljiva u sledećem rasponu: 1-1,24 niska jezička anksioznost, 1,25-1,74 umereno prisutna jezička anksioznost, i 1,75-3 izražena jezička anksioznost. (v. Tabelu 1)

\begin{tabular}{|l|c|c|}
\hline Vrsta jezičke anksioznosti & AS & SD \\
\hline Anksioznost pri komunikaciji & 1,65 & 0,87 \\
\hline Anksioznost u razrednoj situaciji & 1,73 & 0,83 \\
\hline
\end{tabular}

Tabela 1. Pregled prisustva jezičke anksioznosti

Iz priloženih podataka se vidi da su kod učenika šestog razreda anksioznost pri komunikaciji i anksioznost u razrednoj situaciji uopšte, umereno 
prisutne, dok relativno niska standardna devijacija u oba slučaja upućuje na veću homogenost grupe u pogledu određenog ponašanja.

S obzirom da eksterni faktori imaju veliki uticaj na razvoj jezičke anksioznosti, za potrebe ovog rada ispitan je i uticaj nekoliko eksternih faktora na pojavu jezičke anksioznosti u razrednoj situaciji i anksioznosti pri komunikaciji, a to su pol, ocena iz engleskog jezika i pohađanje privatnih časova.

Da bi se uvidelo da li postoji statistički značajna razlika u nivou jezičke anksioznosti između dečaka i devojčica, podaci sakupljeni upotrebom prilagođene verzije skale za merenje jezičke anksioznosti u razrednoj situaciji analizirani su upotrebom $t$-testa. Tabela 2 . daje pregled rezultata $t$-testa za anksioznost $\mathrm{u}$ razrednoj situaciji uopšte i za anksioznost pri komunikaciji. (v. Tabelu 2).

\begin{tabular}{|c|c|c|c|c|c|c|c|}
\hline Učenici 6. razreda & Pol & $\mathrm{N}$ & AS & SD & $\begin{array}{c}\text { Razlika } \\
\text { AS }\end{array}$ & $t$ & $p$ \\
\hline \multirow{2}{*}{$\begin{array}{l}\text { Anksioznost } \\
\text { komunikaciji }\end{array}$} & $\mathrm{M}$ & 75 & 1,82 & 0,49 & \multirow{2}{*}{0,07} & \multirow{2}{*}{,0801 } & \multirow{2}{*}{0,425} \\
\hline & $\check{Z}$ & 67 & 1,75 & 0,51 & & & \\
\hline \multirow{2}{*}{$\begin{array}{ll}\text { Anksioznost } & \mathrm{u} \\
\text { razrednoj situaciji } & \end{array}$} & $\mathrm{M}$ & 75 & 1,79 & 0,36 & \multirow{2}{*}{0,10} & \multirow{2}{*}{1,608} & \multirow{2}{*}{0,110} \\
\hline & Ž & 67 & 1,68 & 0,42 & & & \\
\hline
\end{tabular}

Tabela 2. Jezička anksioznost i pol

Rezultati jasno pokazuju da ne postoji statistički značajna razlika između pola ispitanika i nivoa jezičke anksioznosti ni u slučaju anksioznosti u razrednoj situaciji uopšte, ni u kategoriji anksioznosti pri komunikaciji.

Drugi u nizu eksternih faktora koji se analizira je ocena iz engleskog jezika, koja svakako, može da utiče na nivo jezičke anksioznosti, pa samim tim i na anksioznost pri komunikaciji. Međutim, podaci (v. Tabelu 3) ANOVA testa ukazuju na to da statistički značajna razlika postoji između ocene iz engleskog jezika i anksioznosti u razrednoj situaciji uopšte, ali ne i u slučaju anksioznosti pri komunikaciji, kao jednom od njenih sastavnih delova.

\begin{tabular}{|l|c|c|}
\hline \multirow{2}{*}{ Ocena iz engleskog jezika } & \multicolumn{2}{|c|}{ Šesti razredi } \\
\cline { 2 - 3 } & $\mathrm{F}$ & $\mathrm{p}$ \\
\hline Anksioznost pri komunikaciji & 7,499 & 0,702 \\
\hline Anskioznost u razrednoj situaciji & 4,334 & 0,006 \\
\hline
\end{tabular}

Tabela 3. Jezička anksioznost i ocena iz engleskog jezika 
Nadalje, post-hoc Bonferoni testom se ustanovilo da je anksioznost $u$ razrednoj situaciji prisutnija kod učenika sa višim ocenama iz engleskog jezika.

Još jedan eksterni faktor koji može da ima značajan uticaj kako na nivo jezičke anksioznosti u razrednoj situaciji uopšte tako i na anksioznost pri komunikaciji, je pohađanje privatnih časova engleskog jezika. Upotreba $t$-testa je pokazala da je kod generacije učenika šestog razreda uočena statistički značajna veza između pohađanja dodatnih časova engleskog jezika i jezičke anksioznosti na nivou $p<0,000$ za opštu anksioznost $\mathrm{u}$ razrednoj situaciji, kao i za njenu podvrstu, anksioznost pri komunikaciji (v. Tabelu 4).

\begin{tabular}{|c|c|c|c|c|c|c|c|}
\hline $\begin{array}{l}\text { Da li učiš engleski } \\
\text { jezik van škole }\end{array}$ & Odgovor & $\mathrm{N}$ & AS & SD & $\begin{array}{l}\text { Razlika } \\
\text { AS }\end{array}$ & $t$ & $p$ \\
\hline \multirow{2}{*}{$\begin{array}{l}\text { Anksioznost pri } \\
\text { komunikaciji }\end{array}$} & DA & 56 & 1,61 & 0,42 & \multirow{2}{*}{$-0,44$} & \multirow{2}{*}{$-5,799$} & \multirow{2}{*}{0,000} \\
\hline & $\mathrm{NE}$ & 86 & 2,05 & 0,48 & & & \\
\hline \multirow{2}{*}{$\begin{array}{l}\text { Anksioznost u } \\
\text { razrednoj situaciji }\end{array}$} & DA & 56 & 1,61 & 0,34 & \multirow{2}{*}{$-0,29$} & \multirow{2}{*}{$-4,598$} & \multirow{2}{*}{0,000} \\
\hline & $\mathrm{NE}$ & 86 & 1,90 & 0,38 & & & \\
\hline
\end{tabular}

Tabela 4. Učenje engleskog jezika van škole

Iz predstavljenih podataka se vidi da je anksioznost u razrednoj situaciji izraženija kod učenika koji engleski jezik ne uče van škole $(A S=1,90)$ nego što je to slučaj sa učenicima koji engleski jezik uče privatno $(A S=1,61)$. Slični podaci dobijeni su i u kategoriji anksioznosti pri komunikaciji gde je anksioznost još izraženija $(\mathrm{AS}=2,05)$.

\subsection{Analiza kvantitativnih podataka}

Cilj kvantitativne analize ovog rada je da ustanovi da li su i u kojoj meri su jezička anksioznost u razrednoj situaciji, i njena podvrsta, anksioznost pri komunikaciji, prisutne među ispitanicima i na koji način eksterni faktori utiču na njihovu pojavu. Na osnovu pregleda rezultata i analize srednjih vrednosti može se zaključiti da su jezička anksioznost u razrednoj situaciji, kao i anksioznost pri komunikaciji umereno prisutne među ispitanim učenicima. Ovi rezultati korespondiraju rezultatima drugih autora (Pérez-Paredes \& Martínez-Sánchez 2000; Horwitz et al., 1986; Aida, 1994) pokazujući mala odstupanja u nivou jezičke anksioznosti među učenicima, što dodatno potvrđuje validnost upotrebe prilagođene verzije skale za merenje jezičke anksioznosti u razrednoj situaciji. 
Nakon što se utvrdio nivo prisutnosti jezičke anksioznosti, nakon čega se može izvesti zaključak da su i anksioznost pri komunikaciji i jezička anksioznost u razrednoj situaciji umereno prisutne, autorka je pristupila analizi uticaja eksternih faktora pola, ocene iz engleskog jezika i pohađanja privatnih časova na pojavu istih.

Pol kao osnovni eksterni faktor se prvi analizira u većini radova koji se bave ovom tematikom nije se pokazao bitnim za potrebe ovog istraživanja, jer statistički značajna razlika nije uočena. Da je to i očekivano svedoče rezultati koje je dobio Ezi (Ezzi 2012) koji je utvrdio da se s godinama starosti povećava nivo jezičke anksioznosti kod učenika, a samim tim se i korelacija između nivoa jezičke anksioznosti i pola jasnije ogleda. Prema tome, očekivano je da kod učenika na ranom uzrastu eksterni faktor pola neće značajnije uticati na pojavu i razvoj jezičke anksioznosti, posebno ako se u obzir uzme činjenica da je kod učenika ove dobi (12 godina) afektivni filter još uvek slab da bi se takve razlike uočile. Ezi (Ezzi 2012) navodi da se kod učenika starosti 15-18 godina povećava nivo jezičke anksioznosti na časovima stranog jezika, a samim tim se i javljaju i značajnije razlike između pola i nivoa jezičke anksioznosti.

Drugi u nizu analiziranih eksternih faktora je ocena. Rezultati dobijeni statističkom analizom podataka su veoma interesantni jer u odnosu između ocene i anksioznosti pri komunikaciji statistički značajna razlika nije uočena, dok ona postoji kada je reč o uticaju ocene na nivo anksioznosti u razrednoj situaciji uopšte. I za ovakve rezultate postoji teorijska osnova. Učenici osećaju jezičku anksioznost u razrednoj situaciji jer imaju izraženiju potrebu da zadrže dobre ocene te su samim tim i anksiozniji u strahu da bi im pogrešan odgovor ili nenajavljen kontrolni zadatak mogli uticati na uspeh, što objašnjava činjenicu zašto učenici sa boljim ocenama imaju sklonost ka višem nivou jezičke anksioznosti (Foxman 2004; Ay 2010). Nepostojanje statistički značajne razlike u slučaju odnosa između ocene i anksioznosti pri komunikaciji može se opravdati veoma jednostavno. S obzirom da je jasno da statistički značajna razlika postoji u slučaju anksioznosti u razrednoj situaciji uopšte, a čiji je sastavni deo anksioznost pri komunikaciji (anksioznosti u razrednoj situaciji koja obuhvata sva tri tipa anksioznosti: anksioznost pri komunikaciji, ispitnu anksioznost i strah od negativne društvene evaluacije), jedini zaključak koji se nameće je da učenici zaista ne mogu da budu anksiozni u ovoj kategoriji jer bi to značilo da oni na časovima stranog jezika u razrednoj situaciji uistinu razgovaraju (Yli-Renko 1993). S obzirom da je nastava engleskog jezika u našoj zemlji i dalje koncipirana 
tako da učenici mlađeg uzrasta uglavnom uče gramatičke strukture, a interakcija nastavnik-učenik se svodi na postavljanje pitanja i davanje odgovora, prava komunikacija $\mathrm{u}$ okviru razredne nastave na časovima engleskog jezika nije prisutna. Stoga i ne čudi činjenica da se sve veći broj roditelja odlučuje da svojoj deci obezbedi dodatnu nastavu engleskog jezika, jer je pretpostavka da će deca koja su izloženija stranom jeziku isti bolje i savladati.

Prema tome, poslednji u nizu eksternih faktora koji je analiziran u kvantitativnom delu ovog rada pokazuje da li i na koji način dodatno učenje engleskog jezika utiče na nivo jezičke anksioznosti kod učenika viših razreda osnovne škole. Statistička analiza upotrebom $t$-testa je pokazala da su anksiozniji oni učenici koji engleski jezik ne uče privatno.

Učenici koji dodatno uče engleski jezik van razredne situacije uglavnom pohađaju privatne časove ili idu u privatne škole, te su samim tim i duplo više izloženi uticaju stranog jezika od učenika koji engleski jezik uče samo u okviru redovne nastave. Samim tim je i razumljivo da je anksioznost u razrednoj situaciji izraženija kod onih učenika koji engleski jezik uče samo u školi.

Možemo zaključiti da je ovo kvantitativno istraživanje ukazalo na umereno prisustvo jezičke anksioznosti među učenicima šestog razreda osnovne škole. Analiza eksternih faktora i njihovog uticaja kako na pojavu anksioznosti u razrednoj situaciji uopšte tako i na jedan njen segment - anksioznost pri komunikaciji, svakako je doprinela da se dobiju značajni podaci koji mogu da svedoče o potencijalnim uzrocima jezičke anksioznosti. Upravo iz tih razloga, kvantitativni podaci će se dopuniti kvalitativnima kako bi se uzroci pojave jezičke anksioznosti potvrdili i detaljnije ispitali.

\subsection{Kvalitativno istraživanje}

U okviru ovog odeljka predstavlja se analiza intervjua rađenih s učenicima šestog razreda osnovne škole, koji su prethodno popunili anketu. Svrha je bila da se utvrdi prisustvo jezičke anksioznosti u razrednoj situaciji uopšte, kao i anksioznosti pri komunikaciji. Intervjui sprovedeni sa učenicima transkribovani su od reči do reči, smeh, pauze i oklevanja su označeni, jer je autorka smatrala da su takve pauze u govoru značajne pošto upućuju na stav ispitanika prema određenoj temi.

Nakon transkripcije, autorka je pristupila čitanju transkripata da bi se 340 uverila da su svi transkripti tačni i da bi dobila opštu sliku ovog kvalitativnog 
istraživanja. Potom su, pomoću metode analize sadržaja (engl. content analysis) podaci reorganizovani i podeljeni u tematske kategorije - prvo u manje potkategorije, a potom i u veće ključne kategorije. Takva organizacija sadržaja intervjua omogućila je autorki da otkrije veze, identifikuje obrasce i interpretira podatke (Maxwell 2005: 96). Prateći što je u radovima drugih autora definisano kao analiza bazirana na teoriji (engl. theory-guided analysis), autorka se, analizirajući kvalitativne podatke, oslonila na unapred definisane kategorije i istraživačke zaključke drugih autora na temu jezičke anksioznosti (Arnold 1999; Horwitz 2001; Nuto 2003; Aida 1994), što je olakšalo analizu kvalitativnih podataka. U procesu analize kvalitativnih podataka dobijenih putem intervjua sa učenicima šestog razreda, a za potrebe prethodno pomenute doktorske disertacije iz koje je i proistekao ovaj rad, izdvojilo se mnoštvo kategorija za koje se detaljnijom analizom ispostavilo da imaju značajan uticaj na formiranje jezičke anksioznosti kod učenika osnovne škole. U okviru ovog rada, analiziraće se oni delovi transkripata koji su u direktnoj vezi sa rezultatima kvantitativnog istraživanja.

S obzirom da je cilj ovog rada da utvrdi postojanje jezičke anksioznosti u razrednoj situaciji i analizira anksioznosti pri komunikaciji, kao jednu od njenih podvrsta, autorka je na osnovu podataka iz transkripata intervjua došla do zaključka da je jezička anksioznost u direktnoj vezi sa nivoom samopouzdanja, što potvrđuju i ostala istraživanja na istu temu. Nizak nivo samopouzdanja pri usmenom izražavanju na engleskom jeziku u kombinaciji sa malim brojem časova engleskog jezika u školi, a sve većim zahtevima kako nastavnog plana i programa tako i okoline nalaze se na samom vrhu karakteristika koje najviše doprinose stvaranju jezičke anksioznosti kod učenika (Arnold 1999). Upravo tu činjenicu potvrđuju i ispitanici, koji su svi istakli da se u trenutku usmenog izražavanja na času engleskog jezika stide jer često nisu u stanju da formiraju rečenicu na engleskom jeziku. Učenici šestog razreda priznaju da često pre nego što progovore, rečenice i dalje formulišu na srpskom jeziku i neretko nailaze na problem kada takvu, već osmišljenu rečenicu, treba da kažu na engleskom jeziku. U tim slučajevima, oni ili u potpunosti prestaju da govore, gledaju ispred sebe $\mathrm{i}$ čekaju da im nastavnik dozvoli da sednu ili, ukoliko su slobodniji, pokušavaju da nadomeste nedostatak vokabulara upotrebom reči koje znaju. 
S-4 ${ }^{1}: \quad$ Pa sad, ovako... znate kako, nekad baš znam sve da kažem, posebno ako sam učila. E da, ovaj, a još mi je bolje ako nastavnica nekog pita (smeh), a on ne zna, a ja onda mogu da smislim šta da kažem.

S-11: Joj, nastavnice, pa sad ne znam, znate... meni je gramatika uvek bila loša, ne znam ja ta vremena, pa to da slažem i ... znate na šta mislim.

Autorka: Ajde sad da zaboravimo na gramatiku, nemoj da misliš o tome. Kako bi odgovorio na postavljeno pitanje ako ti se čini da ne znaš baš sve reči?

S-11: Pa, ako ne znam sve reči, pa ne znam... ne bih ništa rekao. Nisam siguran, ne znam ja često sve reči... pa otkud znam, ćutim valjda... da ne kažem još veću glupost i tako to (smeh).

S-3: Hm, pa ovaj, neugodno mi je. Ne znam, ne volim da se ističem.

S-17: Pa ja ćutim i onda vi pitate nekog drugog, a ja sednem...

S-6: Ja mislim da ja... znate ja baš volim engleski... privatno ja idem od trećeg razreda. I mi sa nastavnicom radimo baš tu, ovu knjigu što radimo, znate, ovu u školi što i mi koristimo, pa je to meni sve lako. Meni je nastavnica rekla da kad ne znam neku reč, kažem neku drugu reč koju znam i koja je slična. To onda nema veze, bitno je da nešto kažem. Ne valja da ćutim. Pa da.

S-20: Meni je lepše kad ćutim. Ne volim da se javljam, lakše mi je kad nešto radimo što se piše. Samo da ne moram da govorim... (blagi osmeh).

Sem niskog nivoa samopouzdanja, iz intervjua sa učenicima se nametnuo zaključak da problem sa komunikacijom na engleskom jeziku nije uvek vezan za loše znanje engleskog jezika. Tako, na primer, ispitanici 3 i 20 (S3 i S20), koji imaju odličan odličnu ocenu iz engleskog jezika s polugodišta, takođe izražavaju nesigurnost u svoje znanje kada treba da se usmeno izraze na engleskom jeziku. Ovi podaci korespondiraju podacima drugih autora koji su se bavili proučavanjem ovog problema, a koji su dokazali da nije redak slučaj da su učenici sa odličnim znanjem engleskog jezika i odličnim ocenama ujedno i veoma anksiozni (Horwitz 1996; Gregersen \& Horwitz 2002: 568). Horvic takođe ističe da su često izuzetno kompetentni govornici engleskog jezika nezadovoljni svojim govornim veštinama. Osim nerealističnih zahteva i standarda koje učenici sebi nameću,

${ }^{1}$ Kako bi se zadržala anonimnost učenika, autorka nije koristila njihova imena već kombinaciju slova S i brojeva. Tako se u transkriptima intervjua nalaze ispitanici od S-1 do S-22. 
prethodno pomenut nizak nivo samopouzdanja može dovesti do nedostatka vere $\mathrm{u}$ govorne veštine ili nemogućnosti da svoje znanje engleskog jezika verbalno izraze. Učenici kod kojih je uočen visok nivo jezičke anksioznosti generalno su se plašili da će se „zalediti“ ili „blokirati“ u trenutku kada treba usmeno da se izraze na engleskom jeziku (Horwitz 2001: 118). Nuto (Nuto 2003: 40) saopštava slične rezultate, napominjući da se usmeno izražavanje na stranom jeziku razlikuje od pismenog izražavanja, jer zahteva aktivaciju brojnih opštih i jezičkih kompetencija. To znači da se lakoća i tečnost usmenog izražavanja mogu postići jedino kroz stalnu praksu i iskustvo, a naznake nedostatka navedenog primetili su osnovnoškolci:

S-9: Pa sad, znate kako nastavnice, nije da ja ne volim da pričam, ali mi je glupo, nekako me je sramota. Kako sad ja da pričam kad ne znam. Ja ne idem privatno, znate, mama i tata ne znaju engleski, i onda ja tako i ne mogu da vežbam sa njima. Mislim možda ću znati kasnije kad budem putovao negde pa budem morao da pričam ili kad budem radio. Ali sad nisam nigde išao, mi ove godine nismo išli ni na more.

S obzirom da su ispitanici većim delom izjavili da smatraju da planom i programom predviđena dva časa nisu dovoljna da se savlada engleski jezik u razrednoj situaciji, sledi zaključak da bi uz veću izloženost uticaju engleskog jezika kako u školi tako i van nje, došlo do smanjenja nivoa jezičke anksioznosti kod učenika. Tome u prilog govore i izjave učenika šestog razreda.

S-21: Pa, sad, ne znam... ovaj, nemam baš hrabrosti da govorim, mislim da se ja sad guram i javim. Stidim se ako nešto ne znam. Možda kad bi imali više vremena da sve izvežbamo, to što radimo. Ovako ja ne stignem da naučim.

S-8: $\quad$ Meni nikad nije problem da pričam engleski. Mi puno pričamo tu u školi gde idem privatno. I onda meni nije problem.

Autorka: A da li ti je bio problem da govoriš engleski na času pre nego što si počela privatno da ga učiš?

S-8: Ovaj, pa jeste malo. Ipak je nas tu puno u razredu pa i ne stignemo da kažemo svi po nešto. A i ako radimo neku lekciju, pa dok mi napišemo reči i pročitamo, i šta još... ovaj... radimo, da prevodimo... već zvoni. 
S-5: $\quad$ Ne javljam se ja da pričam. Samo kad baš nešto znam pa da dobijem plus.

U ranijim istraživanjima, kao jedan od najznačajnijih uzroka jezičke anksioznosti u razrednoj situaciji (Horwitz at al. 1986), izdvojen je strah učenika da će u toku usmenog izražavanja na stranom jeziku napraviti grešku. I ovo kvalitativno istraživanje potvrđuje ove navode. Iz transkripata intervjua se može primetiti da je kod učenika koji su opisali ponašanje karakteristično za visok nivo jezičke anksioznosti ujedno izraženiji i strah od greške nego što je to slučaj kod učenika u čijim je odgovorima jezička anksioznost manje izražena. Prema tome, osećaj straha ili panike primećen je kod ispitanika sa slabijim uspehom iz engleskog jezika (S-21, S-16, S-11), dok su ostali ispitanici izrazili nešto blaži oblik straha od greške kao što je neugoda.

S-4: Pa normalno, mislim da pogrešim, to, to mi je normalno zato što ja ne znam taj akcenat.

S-14: Malo se plašim, bojim se kako ću to reći.

S-22: Pa malo sam nesiguran, da nisam dobro naučio i da ću nešto pomešati.

S-21: Onda se već uplašim. Pa malo uplašeno se osećam, da ću pokvariti ono što sam do sada učio, a i da ću dobiti lošu ocenu, a i smeju mi se kada pogrešim, da.

S-11: Onako čudno, nešto mi u stomaku odjednom, i onda ajde, šta sad (smeh).

Autorka: Možeš li da mi objasniš zašto se to dešava?

S-11: Pa ne znam, tako mi je oduvek. Sav se stegnem. I onda ćutim.

S-16: Pa onako, ponekad samo imam veliku tremu.

Autorka: Kako se tada osećaš?

S-16: Pa onako, pocrvenim, sramota me da pričam pred drugima, bojim se da se ne smeju.

Ako se ovaj problem sagleda iz drugog ugla može se primetiti da učenici kod kojih je jezička anksioznost izraženija izbegavaju situacije u kojima se od njih može zahtevati da se izraze na engleskom jeziku, dok učenici čiji odgovori upućuju na niži nivo jezičke anksioznosti, čak i u ovako mladom dobu, ispravljanje greške od strane nastavnika gledaju kao poučnu situaciju koja će im omogućiti da engleski jezik bolje nauče. 
S-3: $\quad$ Pa onako, čudno mi je malo kad me nastavnik ispravi, onako u stomaku mi malo kuva, ali kako drugačije da naučim. Pa mora da me ispravi. Pa mislim, ovaj, znam da to niko ne voli, ali mislim, kako drugačije. I znam ja da je to za moje dobro, znate. Ma znate, nastavnice, i vi znate koliko njih kad nešto pitate sagne glavu samo da ih ne prozovete. Mislim, ja neću tako. Pa šta i ako pogrešim, ovaj, pa vi uvek kažete da nema veze, pa mislim, vi nikom niste dali jedinicu ako pogreši. Nego, lepo me ispravite $i$ onda ja drugi put znam.

S-8: $\quad$ Ne, ne smeta mi, drugi put ću se potruditi da ne pogrešim.

Stavovi učenika i način na koji će reagovati na ispravljanje greške od strane nastavnika u velikoj meri zavise od stava nastavnika stranog jezika, jer se u ranijim istraživanjima pokazalo da način na koji nastavnici ispravljaju greške kod učenika dok govore engleski jezik u velikoj meri utiče na razvijanje jezičke anksioznosti kod učenika, posebno pri usmenom izražavanju (Horwitz et al. 1986; Young 1991; Nuto 2003). U prilog tome govore oštriji komentari poput ovoga:

\section{S-5: Ma, nastavnici samo čekaju da neko pogreši pa da popune dnevnik jedinicama.}

Još jedna u nizu kategorija koja je vezana za anksioznost pri komunikaciji je i strah od iznenadnog prozivanja. Na pitanje iz intervjua „Kako se osećaš kada te nastavnik engleskog jezika iznenada prozove da odgovaraš?" većina ispitanika odmahuje glavom i duboko uzdiše. Njihovi odgovori se temelje na objašnjenju da im prozivanje da odgovaraju bez prethodne najave uzrokuje najveći strah. Strah od iznenadnog prozivanja opisan je i u literaturi (Aida 1994), gde se navodi da je to jedan od najčešćih uzroka jezičke anksioznosti u razrednoj situaciji. Suština ove situacije je da ona izaziva anksioznost u najvećoj meri samo zbog činjenice da u tim momentima učenik nema vremena da se pripremi za odgovaranje. Prema tome, nedostatak vremena da se sabere u kombinaciji sa pritiskom koji oseća jer mora da ustane i da odgovor na postavljeno pitanje dok su sve oči uprte u njega kod učenika neretko dovodi do potpune blokade, kao što se može videti iz opisa ispitanika:

S11: Pa ponekad kada nastavnik nešto objašnjava, a mi pričamo, onda nas prekine i na primer meni kaže, ovaj, postavi mi 
pitanje neko, i onda svi zaćutimo i ja moram da ustanem, i onda svi gledaju u mene.. i ovaj, pa ne znam, ja se onda uplašim i ništa ne znam da kažem. Nekako se blokiram, i onda samo ćutim...

S21: Nekako, stane mi srce, ne znam. Pa ne znam, prvo se bojim jer ne znam da li će me on prozvati. Ako na primer nešto pišem u knjizi ili svesci, i onda... i onda, ne znam, on me prozove, ne znam, bude mi loše. Srce mi stane.

U istraživanjima drugih autora spominju se slične situacije, te se smatra prilično uobičajenim da se visoko anksiozni učenici (koji mogu biti i odlični đaci sa dobrim poznavanjem jezičkih struktura) zamrznu (engl. freeze up) tokom testa ili usmenog odgovaranja (Horwitz et al. 1986: 126). Ova pojava se najčešće objašnjava činjenicom da jezička anksioznost ima mogućnost da u potpunosti ovlada kognitivnim sposobnostima učenika i tako poremeti njihovo izlaganje (McCroskey 1997b: 110). Ona često dovodi do potpune „mentalne blokade” koja utiče na sposobnost učenika da obradi informacije u procesu učenja stranog jezika. U tom slučaju jezička anksioznosti deluje kao afektivni filter, dovodeći učenika u situaciju da uopšte ne reaguje na jezički input (MacIntyre \& Gardner 1991a: 87).

\subsection{Analiza kvalitativnih podataka}

Ako se u obzir uzme sve prethodno navedeno može se zaključiti da je kvalitativna analiza intervjua sa učenicima značajno dopunila kvantitativnom analizom dobijene podatke i prikazala emocije i stavove učenika, njihove strepnje, probleme i očekivanja.

Ispostavilo se da je nizak nivo samopouzdanja u velikom meri uzročnik pojave kako jezičke anksioznosti u razrednoj situaciji uopšte tako i anksioznosti pri komunikaciji. Učenici koje muči ovaj problem, najčešće ne teže visokim ciljevima, što se vidi iz transkripata, zadovoljavaju se ocenom koju imaju i ne žele da privuku pažnju na sebe. Interesantna je činjenica da takvi učenici nisu nužno i loši đaci, već samo izgubljeni u želji da zadrže što bolje ocene i prikriju nemogućnost da se adekvatno izraze na stranom jeziku.

Analiza intervjua je uputila i na činjenicu da je nizak nivo samopouzdanja u velikoj meri povezan sa nedostatkom izloženosti uticaju engleskog jezika što ujedno ukazuje na jednu prednost upotrebe kvalitativnih metoda jer se na ovaj 
način, kroz direktne odgovore učenika uočava povezanost ova dva faktora. Transkripti nam pokazuju da učenici kod kojih se primećuje visok nivo jezičke anksioznosti većim delom nisu u mogućnosti da engleski jezik uče dodatno, što znači da su uticaju engleskog jezika izloženi tek dva puta nedeljno u periodu od jednog školskog časa. Sve navedene činjenice su dodatno povezane sa naredna dva, veoma važna faktora: strahom od greške i strahom od iznenadnog prozivanja. Naime, prilikom pisanja testa ili prozivanja od strane nastavnika, ispitanici su izjavili da osećaju neopisiv strah koji se neretko i fizički ispoljava (nemogućnost govora, bolovi u stomaku, znojenje dlanova, itd.), a koji uglavnom nastaje kao posledica nesigurnosti u sopstveno znanje, straha da će tokom testiranja napraviti grešku i usled toga dobiti lošu ocenu i/ili biti podvrgnuti ruglu od strane vršnjaka iz odeljenja. Ispostavilo se ta toj vrsti straha češće pribegavaju učenici koji stranom jeziku nisu izloženi više od planom i programom propisana dva školska časa. Učenici, koji su engleskom jeziku izloženi češće, nisu u toj meri izrazili strah jer im dodatna izloženost stranom jeziku uliva određenu vrstu sigurnosti:

S-8: $\quad$ Meni nikad nije problem da pričam engleski. Mi puno pričamo tu u školi gde idem privatno. I onda meni nije problem.

\subsection{Diskusija}

S obzirom da je kvantitativnom analizom podataka utvrđeno da je kod ispitanih učenika anksioznost u razrednoj situaciji i anksioznost pri komunikaciji umereno prisutna, autorka je dodatno ispitala pojavu ove dve anksioznosti kroz ranije spomenute eksterne faktore.

Prvi u nizu eksternih faktora koji je analiziran u ovom radu je pol, ali statistički značajni podaci u vezi sa ovim faktorom nisu uočeni. U okviru analize kvalitativnih podataka, autorka takođe nije uočila značajne razlike između devojčica i dečaka, a s obzirom da teorijski podaci govore u prilog tome da se kod učenika na ranom uzrastu ovakve razlike teško uočljive, autorka se nije detaljnije bavila ispitivanjem ovog faktora s obzirom da je kod učenika ovog uzrasta afektivni filter dovoljno slab da takve razlike prođu nezapaženo.

Međutim, kada je reč o narednim eksternim faktorima analiziranim u ovom radu kvantitativni podaci su pokazali da je statistički značajna veza uočena između obe vrste anksioznosti i eksternog faktora koji se odnosi na dodatno učenje engleskog jezika. Daljom analizom se utvrdilo da učenici koji engleski 
jezik ne uče privatno imaju niži nivo jezičke anksioznosti, ali i anksioznosti pri komunikaciji u razrednoj situaciji od učenika koji engleski jezik dodatno pohađaju. Ocena kao značajan eksterni faktor je u okviru kvantitativne analize pokazala sledeće: statistički značajna razlika je uočena između ocene iz engleskog jezika i jezičke anksioznosti u razrednoj situaciji, ali ne i između ocene i anksioznosti pri komunikaciji. Ovaj podatak je u neku ruku bio neočekivan jer se nameće logičan zaključak da ako već postoji statistički značajna razlika između ocene i jezičke anksioznosti uopšte, ista bi trebalo da se manifestuje i pri analizi anksioznosti pri komunikaciji koja je njen sastavni deo. Upravo kod ovakvih situacija se vidi prednost upotrebe mešovitih metoda istraživanja, jer se nakon kvantitativne analize sve nedoumice mogu razjasniti analizom kvalitativnih podataka.

Analizirajući transkripte intervjua autorka je došla do zaključka da, bez obzira na ocenu iz engleskog jezika, učenici šestog razreda osnovne škole opisuju ponašanje karakteristično za jezičku anksioznost u situacijama kada treba da se izraze na engleskom jeziku. Tako se analizom intervjua pokazalo da odlični đaci u određenoj meri teže perfekcionizmu, te stoga žele da iz svakog predmeta, pa tako i iz stranog jezika imaju savršene ocene (S20). Oni pritom smatraju da to podrazumeva jako dobro znanje engleskog jezika i izražavanje koje nema mnogo grešaka. Imaju težnju da pauze u govoru, nemogućnost da se sete određene reči ili fraze, oklevanje i pogrešnu upotrebu glagolskog vremena tumače kao svoju nesposobnost da nauče ono što se od njih traži, dok učenici koji su manje anksiozni (a kako podaci ističu i češće izloženi stranom jeziku) greške vide kao neizbežan deo procesa učenja stranog jezika.

S obzirom na nedoumicu koju su kod autorke izazvali podaci dobijeni kvantitativnim putem, a u vezi sa eksternim faktorom ocene, autorka je detaljnije proučila situacije u kojima su učenici opisali prisustvo anksioznosti pri komunikaciji u intervjuima. Intervjuisani učenici su časove govornih vežbi (gde bi anksioznost pri komunikaciji trebalo da je najizraženija) opisali kroz karakteristike frontalnog načina rada nastavnika gde se interaktivni zadaci baziraju na postavljanju pitanja i davanju odgovora, čitanju tekstova naglas, te prevođenju istih. Učenici nisu spomenuli upotrebu autentičnih materijala $u$ nastavi stranog jezika u okviru intervjua, a pretpostavka autorke je da se autentični materijali koji podstiču usmeno izražavanje i inače retko koriste $u$ nastavi u osnovnoj školi (da li zbog nedostatka motivacije i resursa nastavnika ili zbog nemogućnosti organizovanja interaktivnog rada sa velikim brojem učenika). 
Ovakva razmišljanja autorke odgovarajuću teorijsku osnovu pronalaze u finskoj studiji koja dočarava metodički realnu situaciju koja se odvija na časovima stranog jezika (Alanen 2003). Prema ovoj studiji, metodički principi koji podstiču usmenu upotrebu jezika na času retko se koriste upravo iz prethodno spomenutih razloga. Stoga se neretko dešava da su učenici slobodniji u upotrebi stranog jezika van učionice, kada jezik koriste sa članovima porodice, prijateljima, strancima na putovanju ili u razgovoru putem društvenih mreža sa vršnjacima iz drugih zemalja. U tim situacijama učenici su svesni činjenice da ih niko ne ocenjuje, osećaju se slobodnije, te im je i nivo samopouzdanja veći nego što je to slučaj u razrednoj situaciji. Ključna stavka iz prethodno citirane studije je ,učenici su svesni činjenice da ih niko ne ocenjuje“, što nadalje navodi na zaključak da učenici pri usmenom korišćenju engleskog jezika na času ne razgovaraju već odgovaraju. To se vidi i iz transkripata intervjua sa učenicima šestog razreda gde se u više navrata mogu primetiti izjave ovog tipa:

S-21: Pa malo uplašeno se osećam, da ću pokvariti ono što sam do sada učio a i da ću dobiti lošu ocenu.

Ako na primer nešto pišem u knjizi ili svesci i onda... i onda, ne znam on me prozove, ne znam, bude mi loše. Srce mi stane. Nastavnici samo čekaju da neko pogreši pa da popune dnevnik jedinicama.

S-17: Imamo nekad tekstove gde čitamo po ulogama... da i one vežbe gde odgovaramo na pitanja posle lekcije. Da, to uvek radimo, baš često. A radili smo jednom $\mathrm{i}$ ono, gde ja postavljam Ani pitanja, a onda ona meni.

S-8: Nastavnica postavlja pitanja, mi se javljamo i odgovaramo. Lekciju uvek pročitamo, mislim prvo nastavnica pusti $\mathrm{CD}$, pa onda prevede, i onda se mi javljamo da čitamo.

Iz navedenih izvoda iz intervjua se može zaključiti da nijedan od ovih učenika ne opisuje komunikaciju na engleskom jeziku već situacije u kojima se njihovo izlaganje ocenjuje, tj. situacije u kojima nastavnik prati strukturu udžbenika po kome predaje i od učenika traži da čitaju tekst i odgovaraju na pitanja koja slede nakon njega. Zato i ne čudi podatak da anksioznost pri komunikaciji nije uočena u kvantitativnom delu ovog istraživanja (u odnosu na ocenu iz engleskog jezika) jer ni u kvalitativnim podacima nije uočena ova kategorija. Simptomi jezičke anksioznosti u razrednoj situaciji, opisani u izjavama 
učenika, stoga ne pripadaju kategoriji anksioznosti pri komunikaciji, već se svrstavaju u kategorije niskog nivoa samopouzdanja, straha od greške i ispitne anksioznosti.

Prema tome, kombinacijom kvantitativnih i kvalitativnih podataka može se jasno izvesti zaključak da je hipoteza koja se obrađuje u okviru ovog rada, Anksioznost pri komunikaciji je izražena među učenicima viših razreda osnovne škole, opovrgnuta jer je usmena komunikacija na časovima engleskog jezika u razrednoj situaciji svedena na reprodukciju materijala koji se nalazi u udžbeniku, te pojam anksioznosti pri komunikaciji u razrednoj situaciji nije moguće analizirati.

\section{ZAKLJUČAK}

Istraživanje analizirano za potrebe ovog rada imalo je za cilj da analizom upotrebe kvalitativne paradigme, uputi na značaj i neophodnost upotrebe kvalitativnih instrumenata, u ovom slučaju intervjua, koji su od suštinskog značaja za adekvatno tumačenje kvantitativnih podataka.

U navođenju prednosti i mana kvantitativnog i kvalitativnog istraživanja, ne treba zaboraviti da i jedna i druga strana teže istom cilju - istini. Kvantitativni rezultati obezbeđuju jasne činjenice koje potvrđuju ili pobijaju neku teoriju, ali subjektivni stav svakog ispitanika koji stoji iza prostih činjenica i brojeva dobija se isključivo kvalitativnom analizom. To znači da četvorka jednog ispitanika na Likertovoj skali nije identična četvorci drugog ispitanika iako odgovaraju na isto pitanje. Iza svakog brojčanog odgovora stoji misaoni proces na koji utiču vrednosti i verovanja pojedinca, te je posao istraživača da shvati i predoči drugima da iza odgovora na skali od jedan do pet ipak postoji nešto više. Prema tome, nije čudno što se kvantitativne i kvalitativne metode odlično dopunjuju. Kvalitativno istraživanje je tu da dopuni i nadogradi stare i otkrije nove teorije i varijable koje se uz pomoć kvantitativnih metoda testiraju i objašnjavaju. S obzirom na to da i jednu i drugu metodu istraživanja karakterišu različite slabosti i prednosti, one čine alternativu i nisu međusobno isključive, već se savršeno nadopunjuju. 


\section{LITERATURA}

Aida, Y. (1994). "Examination of Horwitz, Horwitz and Cope's construct of foreign language anxiety: The case of students of Japanese":. The Modern Language Journal 78 (2), 155-168.

Alanen, R. (2003). “A sociocultural approach to young language learners' beliefs about language learning“, in: Beliefs about SLA: New research approaches, eds. P. Kalaja \& A. M. F. Barcelos (Netherlands: Kluwer Academic Publishers): 55-85.

Arnold, J. (1999). Affect in language learning. Cambridge: Cambridge University Press.

Auberbach, C. F. and Silverstein, L. B. (2003). Qualitative data: An introduction to coding and analysis. New York: New York University Press.

Ay, S. (2010). "Young adolescent students' foreign language anxiety in relation to language skills at different levels". The Journal of International Social Research, 3(11): 83-91..

Brinkmann, S. (2008). "Interviewing“, in: The Sage Encyclopedia of Qualitative Research Methods, ed. L. M. Given (Thousand Oaks, CA: Sage Publications, Incorporated): 470-472.

Denzin, N. K. and Lincoln Y. S. Handbook of Qualitative Research. Thousand Oaks: Sage Publications, Inc., 2000.

Ezzi, N. A. (2012). "The impact of gender on the foreign language anxiety of the Yemeni university students". International Journal of Applied Linguistics \& English Literature 1(2): 65-75.

Foxman, P. (2004). The worried child. Berkeley, CA: Hunter House Publishers.

Gregersen, T. and Horwitz, E. (2002). "Language Learning and Perfectionism: Anxious and Non-Anxious Learners' Reactions to their Own Oral Performance". The Modern Language Journal 86 (4): 562-570.

Hirsjärvi, S. and Hurme, H. (2001). Research Interview: The Theory and Practice of Theme Interview. Helsinki: Yliopistopaino.

Horwitz, E. (1996). "Even Teachers Get the Blues: Recognizing and Alleviating NonNative Teachers' Feelings of Foreign Language Anxiety". Foreign Language Annuals 29: 365-372.

Horwitz, E. K. (2001). "Language anxiety and achievement". Annual Review of Applied Linguistics 21: 112-126.

Horwitz, E. K., Horwitz, M. B. and Cope, J. (1986). "Foreign language classroom anxiety". The Modern Language Journal 70: 125-132.

MacIntyre, P. D. and Gardner, R. C. (1991a). "Methods and results in the study of anxiety and language learning: a review of the literature". Language Learning 41 (1): 85-117.

Marshall, C. and Rossman, G. B. (2006). Designing Qualitative Research. Thousand Oaks: Sage Publications.

Maxwell, J. A. (1992). "Understanding and validity in qualitative research", in: The qualitative researcher's companion, ed. A. M. Mile (Thousand Oaks, CA: Sage Publications); 37-64.

McCroskey, J. C. (1997b). "Willingness to Communicate, Communication Apprehension and Self-Perceived Communication Competence: Conceptualization and 
Perspectives“, in: Avoiding Communication. Shyness, Reticence and Communication Apprehension, eds. J. A. Daly, J. C. McCroskey, J. Ayres, T. Hopf and D. M. Ayres (Cresskill, New Jersey: Hampton Press, Inc.): 75-108.

Merton, R. K., Fiske, M. and Kendall, P. (1956). The Focused Interview. A Manual of Problems and Procedures. Glencoe, IL: Free Press.

Nuto, E. (2003). Subjective Experiences of Communication Apprehension in English. University of Jyväskylä. Master's Thesis.

Patton, M. Q. (2002). Qualitative Research and Evaluation Methods. Thousand Oaks, CA: Sage Publications, Inc.

Pérez-Paredes, P. F. and Martínez-Sánchez, F. (2000/2001)“. A Spanish version of the foreign language classroom anxiety scale: Revisiting Aida's factor analysis". Resla v. 14: 337-352.

Radić-Bojanić, B. (2012). “Uloga kvalitativnog istraživanja u primenjenoj lingvistici”, u: Jezici i kulture u vremenu i prostoru, ur. Snežana Gudurić (Novi Sad: Filozofski fakultet): 309-318.

Schensul, J. J. (2008). "Methods", in: The Sage Encyclopedia of Qualitative Research Methods. Thousand Oaks: SAGE Publications: 521-526.

Seale, C. (2003). "Quality in qualitative research", in: Turning points in qualitative research, ed. Y. S. Denzin (Walnut Creek, CA: AltaMira Press): 169-184.

Walsh, K. (2003). "Qualitative research: Advancing the science and practice of hospitality". Cornell Hotel and Restaurant Administration Quarterly 44 (2): 6674.

Yli-Renko, K. (1993). Intercultural Communication in Foreign Language Education. Research Reports A: 168: University of Turku. Faculty of Education.

Radmila Suzić

QUALITATIVE RESEARCH IN APPLIED LINGUISTICS: THE IMPORTANCE AND SIGNIFICANCE OF THE INTERVIEW IN FOREIGN LANGUAGE ANXIETY RESEARCH

Summary

This paper aims to highlight the importance of the use of qualitative research methods in applied linguistics. Through a detailed theoretical review of the literature supporting the validity of the use of qualitative data, special attention is given to the interview - an instrument that gives a detailed and unambiguous insight into the perspective of the respondents. The practice is that in the field of applied linguistics quantitative research methods are often combined with qualitative ones in order to obtain a more complete picture and to visualize the research problem from the inside, by allowing respondents to describe the essence of the problem in their own words. As an example of the aforementioned theoretical assumptions, this paper provides a detailed overview of the use of qualitative research methods in the study of language anxiety in a classroom situation, 
and communication apprehension among primary school students, wherein the results obtained using the interview, a qualitative instrument, affect the final interpretation of the results obtained by quantitative research. It can be concluded that quantitative results provide clear facts that confirm or refute a theory, while the subjective aspect of the research issue that lies in each respondent can be gained only through qualitative analysis. Behind every numerical value there are cognitive processes that affect the values and beliefs of individual students, so it is the researcher's task to intertwine quantitative and qualitative methods and present the research issue from both angles.

Keywords: foreign language anxiety, communication apprehension, interview, qualitative research, EFL.

Primljeno: 31.5.2017.

Prihvaćeno: 21.9.2017. 